\title{
Zr-doped indium oxide electrodes: Annealing and thickness effects on microstructure and carrier transport
}

\author{
Esteban Rucavado, ${ }^{1}$ Federica Landucci, ${ }^{1,2}$ Max Döbeli, ${ }^{3}$ Quentin Jeangros, ${ }^{1}$ Mathieu Boccard, ${ }^{1}$ Aïcha Hessler-Wyser, ${ }^{1}$ \\ Christophe Ballif, ${ }^{1}$ and Monica Morales-Masis $\mathbb{C}^{4, *}$ \\ ${ }^{1}$ École Polytechnique Fédérale de Lausanne (EPFL), Institute of Microengineering (IMT), Photovoltaics and Thin Film Electronics \\ Laboratory, Rue de la Maladière 71b, CH-2002 Neuchâtel, Switzerland \\ ${ }^{2}$ École Polytechnique Fédérale de Lausanne (EPFL), School of Basic Sciences (SB), Electron Spectrometry and Microscopy \\ Laboratory (LSME), CH-1015 Lausanne, Switzerland \\ ${ }^{3}$ Swiss Federal Institute of Technology (ETH), Ion Beam Physics, Otto-Stern-Weg 5, CH-8093 Zurich, Switzerland \\ ${ }^{4}$ MESA+ Institute for Nanotechnology, University of Twente, 7500 AE Enschede, The Netherlands
}

(Received 15 April 2019; published 29 August 2019)

\begin{abstract}
$\mathrm{Zr}$-doped indium oxide $\left(\mathrm{In}_{2} \mathrm{O}_{3}: \mathrm{Zr}\right)$ has been shown to satisfy the requirements of low resistance, wide band gap, and high infrared transmittance for application as a front contact in broadband solar cells. However, the reduction of indium usage in front of transparent electrodes is still an unsatisfied requirement. With the goal of reducing the amount of indium while leveraging its properties, in this work, $\operatorname{In}_{2} \mathrm{O}_{3}: \mathrm{Zr}$ films with reduced thickness compared to those standardly used in solar cells are studied. 100 to 15 -nm-thick films were sputtered at room temperature and annealed in distinct atmospheres to study the links between thickness, microstructure, and optoelectronic properties. As-deposited films exhibit an amorphous microstructure embedding bixbyite $\mathrm{In}_{2} \mathrm{O}_{3}$ nanocrystals. Annealing in neutral $\left(\mathrm{N}_{2}\right)$ or reducing atmosphere $\left(\mathrm{H}_{2}\right)$ allows a slight growth of these crystallites but the layers remain mostly amorphous. Whereas annealing in air results in polycrystalline films with an average grain lateral size ranging from 350 to $500 \mathrm{~nm}$. The large crystalline grains formed during air annealing lead to increased electron mobility for all thickness: up to $100 \mathrm{~cm}^{2} \mathrm{~V}^{-1} \mathrm{~s}^{-1}$ for 100 -nm-thick films and up to $50 \mathrm{~cm}^{2} \mathrm{~V}^{-1} \mathrm{~s}^{-1}$ for 15 -nm-thick films, which is remarkable for such thin polycrystalline films. Conversely, $\mathrm{H}_{2}$ annealing ensures high free-carrier densities $\left(>1 \times 10^{20} \mathrm{~cm}^{-3}\right)$ but not high mobilities, still achieving conductivities between 1000 and $2000 \mathrm{~S} \mathrm{~cm}^{-1}$, with the films less than 50 -nm-thick keeping high broadband transmittance. The possibility of thinning down $\operatorname{In}_{2} \mathrm{O}_{3}: \mathrm{Zr}$ to a few tens of nanometers while keeping both high lateral conductivity and good transparency makes this material a promising candidate to reduce the amount of indium in optoelectronic applications, such as flexible touch screens and solar cells.
\end{abstract}

DOI: 10.1103/PhysRevMaterials.3.084608

\section{INTRODUCTION}

Transparent conductive oxides (TCOs) are required in various emerging and established technologies such as light emitting diodes, smart windows, and solar cells. Optimal transparent electrodes should have a high lateral conductivity and a low parasitic absorption over a broad range of the spectra [1-3]. Tin-doped indium oxide $\left(\mathrm{In}_{2} \mathrm{O}_{3}: \mathrm{Sn}\right.$ or ITO) has been for many years the mainstream material in industry for such applications, due to its optoelectronic properties but also stability in various environments and ease for processing (both for film deposition and target fabrication) [4-6]. Nonetheless, its optoelectronic properties have limitations: a high free-carrier density $\left(N_{e}\right.$, typically from $10^{20}$ to $10^{21} \mathrm{~cm}^{-3}$ ) is necessary to achieve a high conductivity but this usually results in relatively low electron mobility (typically $\mu<$ $40 \mathrm{~cm}^{2} \mathrm{~V}^{-1} \mathrm{~s}^{-1}$ ) [7] and a high free-carrier absorption. In contrast, hydrogenated and annealed indium oxide $\left(\mathrm{In}_{2} \mathrm{O}_{3}: \mathrm{H}\right)$ has excellent optoelectronic properties due to its high mobility $\left(\mu \sim 100 \mathrm{~cm}^{2} \mathrm{~V}^{-1} \mathrm{~s}^{-1}\right)$, and relatively low free-carrier density

\footnotetext{
*m.moralesmasis@utwente.nl
}

$\left(\sim 10^{20} \mathrm{~cm}^{-3}\right)$, leading to a low free-carrier absorption [8,9]. During deposition of $\mathrm{In}_{2} \mathrm{O}_{3}: \mathrm{H}$, the introduction of water leads to the formation of an amorphous microstructure [10]. A postdeposition thermal annealing at temperatures above $150{ }^{\circ} \mathrm{C}$ crystallizes the film and improves $\mu$ and the optical properties. Deposition without introduction of water results in films that are already polycrystalline but with low electron mobility $\left(\sim 10 \mathrm{~cm}^{2} \mathrm{~V}^{-1} \mathrm{~s}^{-1}\right)$, which does not increase drastically after a subsequent thermal treatment $\left(\sim 30 \mathrm{~cm}^{2} \mathrm{~V}^{-1} \mathrm{~s}^{-1}\right)$ [11].

Experimental and computational studies have described extensively the doping, transport, and crystallization mechanisms of $\mathrm{In}_{2} \mathrm{O}_{3}: \mathrm{H}$. Experimental results [8,9,12] suggest that hydrogen plays a key role in reducing the number of defects in the films, presumably as it substitutes oxygen vacancies $\left(\mathrm{V}_{\mathrm{O}}{ }^{++}\right)$, with the resulting defect complex $\left(\mathrm{H}_{\mathrm{O}}{ }^{+}\right)$ scattering less free charges but still providing some free carriers. This effect, combined with the overall reduction of structural disorder by crystallizing the films, increases the mobility. By carefully analyzing Hall effect results and optical mobility calculations, the authors found that for 70-nm-thick $\mathrm{In}_{2} \mathrm{O}_{3}: \mathrm{H}$ films, the dominant scattering mechanisms were ionized impurities and phonon scattering. In this regard, previous experimental evidences [13] and scattering calculations 
[14] have shown that for $\operatorname{In}_{2} \mathrm{O}_{3}: \mathrm{H}$ polar optical phonons are dominant over acoustic phonons. In addition, first-principle studies using density functional theory (DFT) have detailed the formation energy of H-related defects [15] and it was found that substitutional and interstitial hydrogen atoms $\left(\mathrm{H}_{\mathrm{O}}{ }^{+}\right.$ and $\mathrm{H}_{\mathrm{i}}{ }^{+}$) act as shallow donors in $\operatorname{In}_{2} \mathrm{O}_{3}: \mathrm{H}$. A complementary study performed by Macco et al. [13] supports these results for 75-nm-thick atomic-layer-deposited films.

After the success of $\operatorname{In}_{2} \mathrm{O}_{3}: \mathrm{H}$, a plethora of In-based TCOs has been investigated with other extrinsic dopants deposited introducing water during deposition, a source of molecular hydrogen $[11,16]$ or by carefully controlling the deposition base pressure [17]. As an example of these materials, substitutional doping using tungsten, cerium, and molybdenum results in In-based oxides with high electron mobilities and free-carrier densities $\left(N_{e}\right.$ of $1.9 \times 10^{20}, 1.1 \times 10^{20}$, and $1.9 \times 10^{20} \mathrm{~cm}^{-3}$ and $\mu$ of 104,110 , and $95 \mathrm{~cm}^{2} \mathrm{~V}^{-1} \mathrm{~s}^{-1}$ for W-doped, Cedoped, and Mo-doped $\mathrm{In}_{2} \mathrm{O}_{3}$, respectively) [18-22]. Another metal-doped $\mathrm{In}_{2} \mathrm{O}_{3}$ with promising optoelectronic properties is $\mathrm{Zr}$-doped indium oxide $\left(\operatorname{In}_{2} \mathrm{O}_{3}: \mathrm{Zr}\right)[23,24]$. Koida et al. demonstrated that epitaxial films of $250 \mathrm{~nm}$ of $\operatorname{In}_{2} \mathrm{O}_{3}: \mathrm{Zr}$ grown at $650{ }^{\circ} \mathrm{C}$ show $\mu$ of $110 \mathrm{~cm}^{2} \mathrm{~V}^{-1} \mathrm{~s}^{-1}$ and $N_{e}$ of $10^{20} \mathrm{~cm}^{-3}$ [24]. Additionally, the same group demonstrated the feasibility to sputter 270-nm-thick $\mathrm{In}_{2} \mathrm{O}_{3}: \mathrm{Zr}$ films with a $\mu>80 \mathrm{~cm}^{2} \mathrm{~V}^{-1} \mathrm{~s}^{-1}$ and a $N_{e}$ of $\sim 3 \times 10^{20} \mathrm{~cm}^{-3}$ at a substrate temperature of $450^{\circ} \mathrm{C}$ [8]. For these films, Zr-doping increased the electrical conductivity. Indeed, in concentrations $\leqslant 2$ at $\%, \mathrm{Zr}$ atoms were found to act as efficient substitutional dopants for $\left.\operatorname{In}_{\left(\mathrm{Zr}_{\mathrm{In}}\right.}{ }^{+}\right)$, while the additional oxygen reduced the concentration of $\mathrm{V}_{\mathrm{O}}{ }^{++}$[24-26]. In addition, $\mathrm{Zr}^{4+}$ and $\mathrm{In}^{3+}$ have similar ionic radii (72 and 80 p.m., respectively [27]), indicating that $\mathrm{Zr}$ is not expected to affect the lattice constant and will not induce lattice strain. Density function theory (DFT) calculations have also indicated that dopants such as Ce [28] and $\mathrm{Zr}$ [29] do not modify the bottom of the conduction band (i.e., $\mathrm{Ce}$ and $\mathrm{Zr}$ orbitals do not hybridize with the indium orbitals), resulting in much lower carrier scattering-hence higher electron mobilities-as compared to ITO.

Recently, we have demonstrated low-temperature fabrication of $\mathrm{In}_{2} \mathrm{O}_{3}: \mathrm{Zr}$ with electron mobility $>100 \mathrm{~cm}^{2} \mathrm{~V}^{-1} \mathrm{~s}^{-1}$ and free-carrier densities $>2.5 \times 10^{20} \mathrm{~cm}^{-3}$ and an average absorptance of $3.6 \%$ (between 390 and $2000 \mathrm{~nm}$ ) for 100$\mathrm{nm}$-thick films on glass [30]. The high lateral conductivity of $4200 \mathrm{~S} \mathrm{~cm}^{-1}$, the band gap of $3.9 \mathrm{eV}$, and low free-carrier absorption place $\operatorname{In}_{2} \mathrm{O}_{3}: \mathrm{Zr}$ as an ideal choice for broadband transparent electrodes. This work aims to further investigate the properties of this material by depositing layers with thicknesses ranging from 15 to $100 \mathrm{~nm}$, submit these films to annealing in various atmospheres, and present an analysis of the scattering mechanisms and their relation to the microstructure and thickness of the films.

\section{EXPERIMENT}

$\mathrm{In}_{2} \mathrm{O}_{3}: \mathrm{Zr}$ films were deposited at room temperature onto aluminoborosilicate glass substrates using a Leybold Univex sputtering system from a target with a 98/2 wt \% composition ratio of $\mathrm{In}_{2} \mathrm{O}_{3} / \mathrm{ZrO}_{2}$. Details of the deposition parameters and optoelectronic properties optimization with oxygen ratio are described in Ref. [30]. In short, the RF power density was fixed to $0.95 \mathrm{~W} / \mathrm{cm}^{2}$ (target diameter of $10 \mathrm{~cm}$ ) and the deposition atmosphere was a mixture of argon and oxygen. The optimal $\mathrm{O}_{2} /\left(\mathrm{Ar}+\mathrm{O}_{2}\right)$ flow ratio was set to $0.3 \%$. A base pressure of $1.0 \times 10^{-6} \mathrm{mbar}$ was used for all depositions. After deposition, the films were annealed at $200{ }^{\circ} \mathrm{C}$ for $30 \mathrm{~min}$ in air or in a pressure of 0.5 mbar of $\mathrm{H}_{2}$ or $\mathrm{N}_{2}$. Film thicknesses were measured using an Ambios XP-2 contact profilometer.

The Hall electron mobility $(\mu)$ and free-carrier density $\left(N_{e}\right)$ of the films were measured using a HMS-3000 Hall effect system in the Van der Pauw configuration. Total reflectance $(T R)$ and total transmittance $(T T)$ were measured with a PerkinElmer Lambda 900 spectrophotometer. The absorptance $(A)$ of the films was calculated as follows: $A=$ $100-T T-T R$, which is a good approximation for highly transparent materials.

The microstructure of the films was analyzed by transmission electron microscopy (TEM) using an FEI Tecnai Osiris operated at $200 \mathrm{kV}$. For that purpose, films were deposited on carbon-coated $\mathrm{Cu}$ grids. Scanning TEM (STEM) images and selected-area diffraction patterns (SAED) were acquired in a top view configuration to characterize the microstructure and the crystallography of the films. Energy dispersive $\mathrm{x}$ rays analysis (EDX) was conducted using four silicon drift detectors [31]. The composition of the films was also obtained using Rutherford backscattering spectrometry (RBS) with 2 and $5 \mathrm{MeV}$ He ions and a silicon PIN diode detector under $168^{\circ}$ [32]. Hydrogen depth profiles were measured by elastic recoil detection analysis (ERDA) with a $2 \mathrm{MeV} \mathrm{He}$ ion beam applying the absorber foil technique [32].

\section{RESULTS AND DISCUSSION}

\section{A. Microstructure: Effect of thermal annealing under distinct atmospheres}

Figure 1 shows STEM high-angle annular dark field (HAADF) images and selected-area electron diffraction patterns of 50-nm-thick films after deposition and then annealing at $200{ }^{\circ} \mathrm{C}$ in air, $\mathrm{H}_{2}$, or $\mathrm{N}_{2}$. The as-deposited film [Fig. 1(a)] exhibits a predominantly amorphous microstructure, as confirmed by the diffuse rings in the diffraction pattern in Fig. 1(e). Small (average size of $2 \mathrm{~nm}$ ) randomly distributed $\mathrm{In}_{2} \mathrm{O}_{3}$ body-centered cubic bixbyitelike nanocrystals (white and black spots marked by red arrows) are embedded in this amorphous matrix. Similar microstructures have been reported elsewhere [9]. After thermal annealing at $200{ }^{\circ} \mathrm{C}$ in air, these crystallites grow until impingement, resulting in polycrystalline $\operatorname{In}_{2} \mathrm{O}_{3}: \mathrm{Zr}$ films [Figs. 1(b) and 1(f)]. The annealed films show crystalline domains of an average size of $340 \mathrm{~nm}$ (calculated using the average intercept method, in which lines of length $L$ are drawn across the top view micrographs and the $N$ number of intercepts are summed up to calculate the grain size by dividing $L$ by $N$ ). The diffraction pattern of one grain shown in Fig. 1(f) is for a single grain oriented along the [111] orientation (indexed using the software JEMS [33] with the $\mathrm{In}_{2} \mathrm{O}_{3}$ bixbyite atomic structure). Contrary to the films annealed in air, the films annealed in $\mathrm{H}_{2}$ and $\mathrm{N}_{2}$ did not trigger a sufficient crystallite growth to reach full crystallization after $30 \mathrm{~min}$ of annealing [Figs. 1(c) and 1(d)]. Corresponding diffraction patterns confirm that 


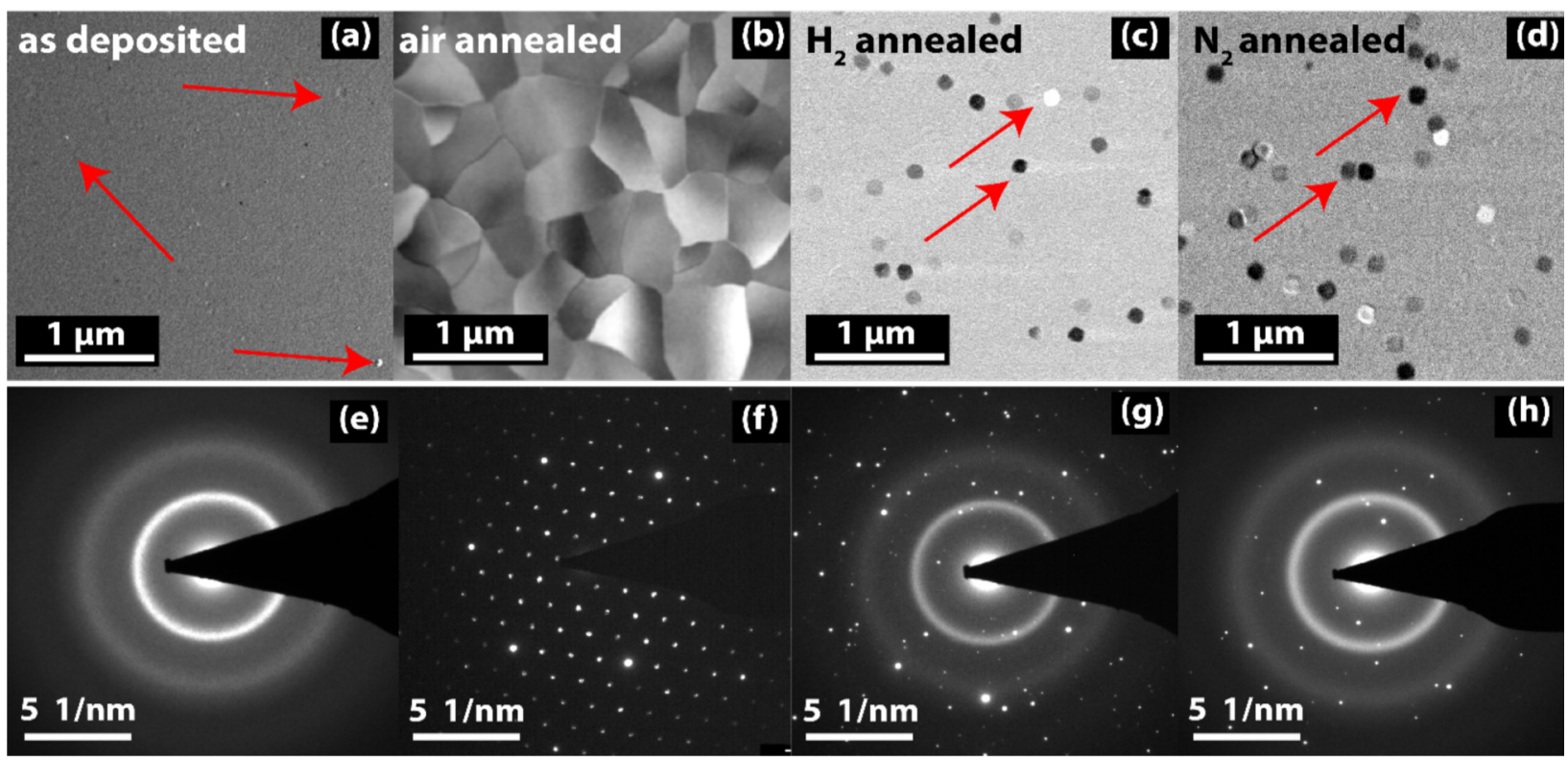

FIG. 1. STEM high-angle annular dark-field (HAADF) images of $\operatorname{In}_{2} \mathrm{O}_{3}: \mathrm{Zr}$ 50-nm-thick films as-deposited (a) and annealed in air (b), $\mathrm{H}_{2}$ (c), and $\mathrm{N}_{2}$ (d). Corresponding diffraction patterns are shown in (e)-(h). The diffraction pattern shown in (f) corresponds to a single grain area of the film annealed in air. All films were annealed for $30 \mathrm{~min}$ at $200{ }^{\circ} \mathrm{C}$. The red arrows indicate the position of nanocrystallites in the films.

the films present an amorphous phase (diffused rings) with embedded crystallites (slightly bigger in size than the present nanocrystallites in the as-deposited state), giving rise to sharp reflections in the diffraction patterns of Figs. 1(g) and 1(h).

Note however that full crystallization after longer annealing times was however observed in the absence of oxygen in the ambient (not discussed here). The presence of $\mathrm{O}_{2}$ in the annealing atmosphere hence seems to accelerate the grain growth process. RBS data indicate that the composition changes from $\mathrm{Zr}_{0.01} \mathrm{In}_{0.40} \mathrm{O}_{0.59}$ in the as-deposited state to $\mathrm{Zr}_{0.01} \mathrm{In}_{0.38} \mathrm{O}_{0.61}$ after annealing in air, indicating that molecular oxygen from the atmosphere is able to adsorb, dissociate, and diffuse into the layer in these annealing conditions. Details of the RBS measurements, including the RBS spectrum and RUMP simulation, are available in Supplemental Material [34]. This slight change in composition modifies the O-In-O coordination and seems to promote the growth of crystalline domains. This was previously proposed for $\operatorname{In}_{2} \mathrm{O}_{3}$ in Refs. [35-38]. These reports show that the crystallization temperature depends on the $\mathrm{In} / \mathrm{O}$ ratio, the deposition temperature and ultimately the route of oxygen incorporation $[35,36,39,40]$.

\section{B. Electronic properties: Effect of thickness and thermal annealing}

Figures 2(a)-2(c) show the electrical properties of 15- to 100-nm-thick $\mathrm{In}_{2} \mathrm{O}_{3}: \mathrm{Zr}$ films before and after annealing in various atmospheres. A systematic change of $N_{e}$ is observed upon annealing for all thicknesses, which depends on the atmosphere. Small or no change is observed for the films annealed in a reducing atmosphere $\left(\mathrm{H}_{2}\right)$, whereas a significant $N_{e}$ drop is observed for the films annealed in air. The $N_{e}$ of the films annealed in a neutral environment $\left(\mathrm{N}_{2}\right)$ lies in between the reducing or oxidizing conditions.
In terms of thickness, $N_{e}$ drops when the layer thickness is reduced from 100 to $15 \mathrm{~nm}$, especially for air-annealed films (from $2.5 \times 10^{20}$ down to $0.5 \times 10^{20} \mathrm{~cm}^{-3}$ ). The mainly amorphous as-deposited films exhibit the highest $N_{e}$ when the thickness is $15 \mathrm{~nm}$, with a value as high as $2.5 \times 10^{20} \mathrm{~cm}^{-3}$.

Regarding mobility, as-deposited films show a $\mu$ of $30-$ $40 \mathrm{~cm}^{2} \mathrm{~V}^{-1} \mathrm{~s}^{-1}$ without any strong thickness dependence. For all thicknesses, annealing in air leads to the highest $\mu$, the highest value of $104 \mathrm{~cm}^{2} \mathrm{~V}^{-1} \mathrm{~s}^{-1}$ being reached for the 100 $\mathrm{nm}$-thick film. For samples annealed in air, the thickness has a marked influence, which will be discussed in detail below. For all the annealing atmospheres, the thinnest films reach a $\mu$ above $40 \mathrm{~cm}^{2} \mathrm{~V}^{-1} \mathrm{~s}^{-1}$, which is remarkable for such thin, room-temperature sputtered films. For as-deposited and $\mathrm{H}_{2}$ annealed films, the combination of $\mu \sim 40 \mathrm{~cm}^{2} \mathrm{~V}^{-1} \mathrm{~s}^{-1}$ and $N_{e} \sim 2 \times 10^{20} \mathrm{~cm}^{-3}$ results in sheet resistance $\left(R_{\mathrm{sh}}\right)$ close to $500 \Omega /$ sq for 15 -nm-thick films and $200 \Omega$ /sq for $25-\mathrm{nm}$ thick films. On the other hand, air-annealed 100- and 50-nmthick films yield a $R_{\mathrm{sh}}$ of 25 and $100 \Omega /$ sq, respectively. The latter is similar to 100 -nm-thick ITO layers, but at half the thickness [1].

Three possible dopants could influence $N_{e}$ in $\mathrm{Zr}$-doped $\mathrm{In}_{2} \mathrm{O}_{3}$ films, namely: $\mathrm{Zr}_{\mathrm{In}}^{+}$atoms, atomic hydrogen $\left(\mathrm{H}_{\mathrm{i}}{ }^{+}\right.$and $\mathrm{H}_{\mathrm{O}}{ }^{+}$), and oxygen vacancies $\left(\mathrm{V}_{\mathrm{O}}{ }^{++}\right)$.

RBS data indicates that the $\mathrm{Zr}$ content remains constant before and after annealing and EDX results show that $\mathrm{Zr}, \mathrm{O}$, and In are distributed homogeneously in the as-deposited and annealed layers (Supplemental Material Fig. S4 [34]). Both highlighting that a change in density of $\mathrm{Zr}$ atoms are not the cause of the changes in $N_{e}$ during the thermal treatments. A change of active dopant density, however, cannot be excluded due to the possible oxidation of the $\mathrm{Zr}^{4+}$ [29].

ERDA shows that annealing in air leads to a reduction of the hydrogen content from 2.3 to 1.8 at \%. It should be mentioned that the presence of $\mathrm{H}$ is expected as it is ubiquitous 

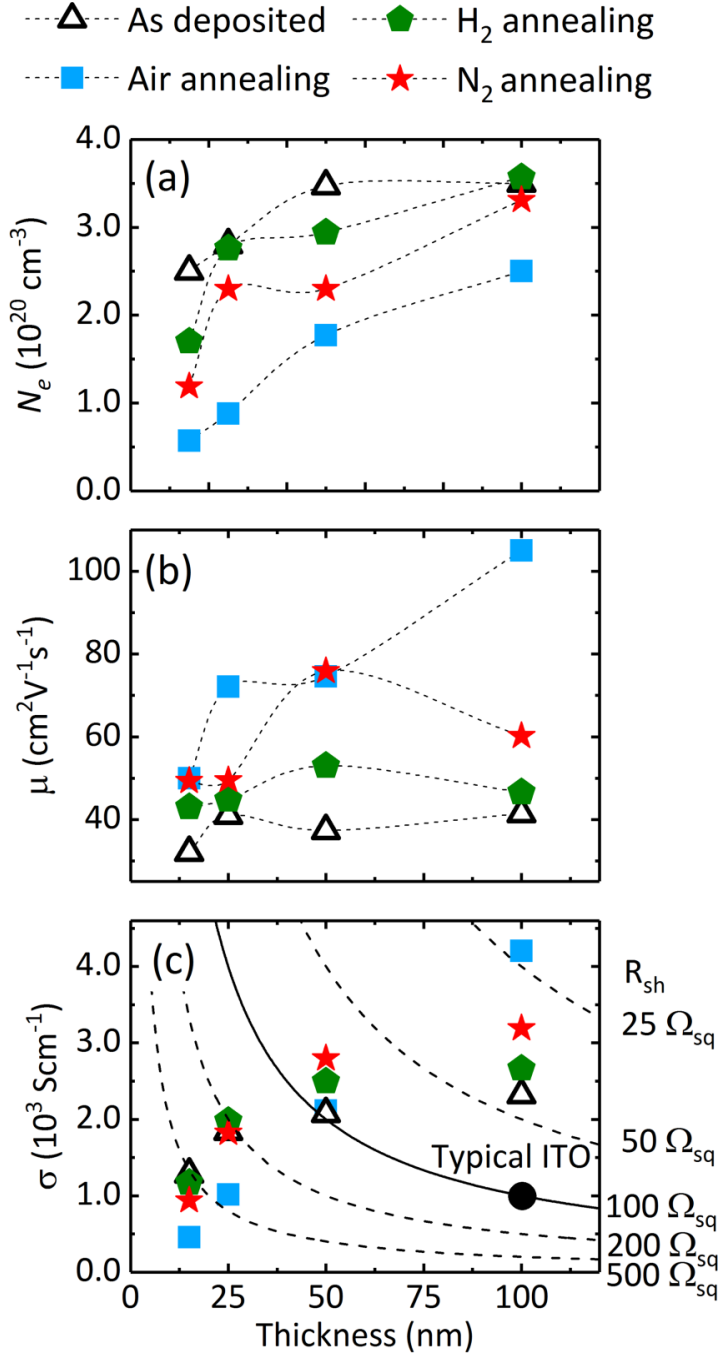

FIG. 2. Free-carrier density (a), Hall mobility (b), and conductivity (c) of $\operatorname{In}_{2} \mathrm{O}_{3}$ : $\mathrm{Zr}$ films as-deposited (empty symbols) and annealed in air, $\mathrm{H}_{2}$, and $\mathrm{N}_{2}$ atmospheres (blue, green, and red full symbols, respectively) as a function of thickness. Overall all properties improve with increasing thickness, and the effect of annealing depends strongly on the annealing atmosphere. Dotted lines in (a) and (b) are guides for the eye, whereas dashed lines in (c) are iso-sheetresistance curves (with the $100 \Omega$ /sq one in solid line). Notably films only 50 -nm-thick present sheet resistances less than $100 \Omega$ /sq.

in deposition systems at a base pressure of $10^{-6}$ mbar. For comparison, $\operatorname{In}_{2} \mathrm{O}_{3}: \mathrm{H}$ sputtered in the presence of $\mathrm{H}_{2} \mathrm{O}$ vapor has a higher $\mathrm{H}$ content of 2.7 at \% in the as deposited state, a value that does not change during annealing.

This change in $\mathrm{H}$ content in $\mathrm{In}_{2} \mathrm{O}_{3}: \mathrm{Zr}$ can explain the drop in $N_{e}$ occurring during annealing in two ways: (i) structural rearrangements could promote hydrogen to replace $\mathrm{V}_{\mathrm{O}}{ }^{++}$ (to form $\mathrm{H}_{\mathrm{O}}{ }^{+}$), decreasing the overall free carrier density [9], and (ii) at $200{ }^{\circ} \mathrm{C}$ hydrogen effusion reduces the $\mathrm{H}_{\mathrm{i}}{ }^{+}$content, also decreasing the free carrier concentration $[15,19]$. Furthermore, the $2 \%$ absolute increase in oxygen content measured by RBS after crystallization also suggests a passivation of $\mathrm{V}_{\mathrm{O}}{ }^{++}$(or oxidation of $\mathrm{Zr}^{4+}$ as mentioned above) which would lower $N_{e}$. The lower point defect density implies lower density
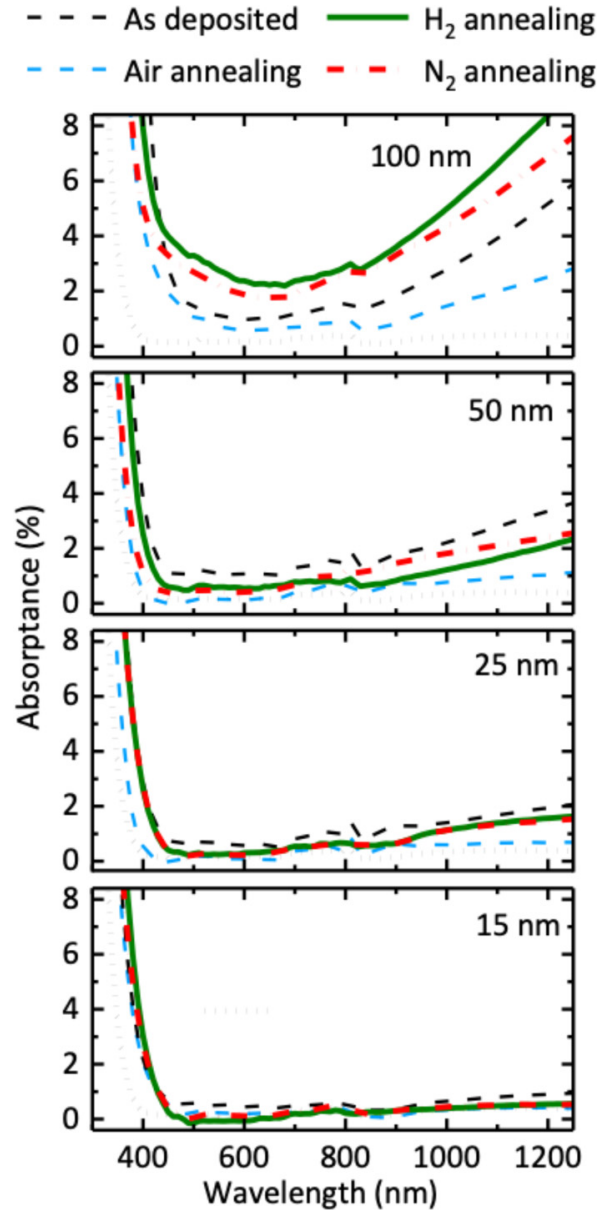

FIG. 3. Optical absorptance as a function of wavelength of the $\mathrm{In}_{2} \mathrm{O}_{3}: \mathrm{Zr}$ films as-deposited and annealed in air, $\mathrm{H}_{2}$, and $\mathrm{N}_{2}$ atmospheres for various thicknesses.

of scattering centers, increasing the average time between scattering events $(\tau)$, which results in a further increase in $\mu$ (as $\mu=e \tau / m^{*}$, where $e$ is the elementary charge and $m^{*}$ the electron effective mass). The drop in $N_{e}$ for the films annealed in air is at least partly related to the oxidation of the layer, whereas the neutral and reducing atmospheres prevent this oxidation. Previous studies have shown that $\mathrm{H}_{2}$ annealing could lead to a reduction of the oxide, creating additional $\mathrm{V}_{\mathrm{O}}{ }^{++}$, or to a doping through $\mathrm{H}$ incorporation $[7,41-45]$.

\section{Optical properties}

Figure 3 shows optical properties of the aforementioned films. The air-annealed films are the most transparent for all thicknesses. This correlates with these showing the largest $\mu$ and lowest $N_{e}$ (coming with the crystallization), and thus the lowest free carrier absorption. Then, for 50- to 15 -nm-thick films, a decrease in absorption is also seen upon annealing in the other atmospheres. The 100-nm-thick film behaves differently and annealing in a reducing or neutral atmosphere leads to an absorptance increase for all wavelengths. This higher absorption in spite of similar electrical properties could be explained by a possible higher density of defects and distinct microstructure of the $\mathrm{H}_{2}$ and $\mathrm{N}_{2}$ annealed samples as 

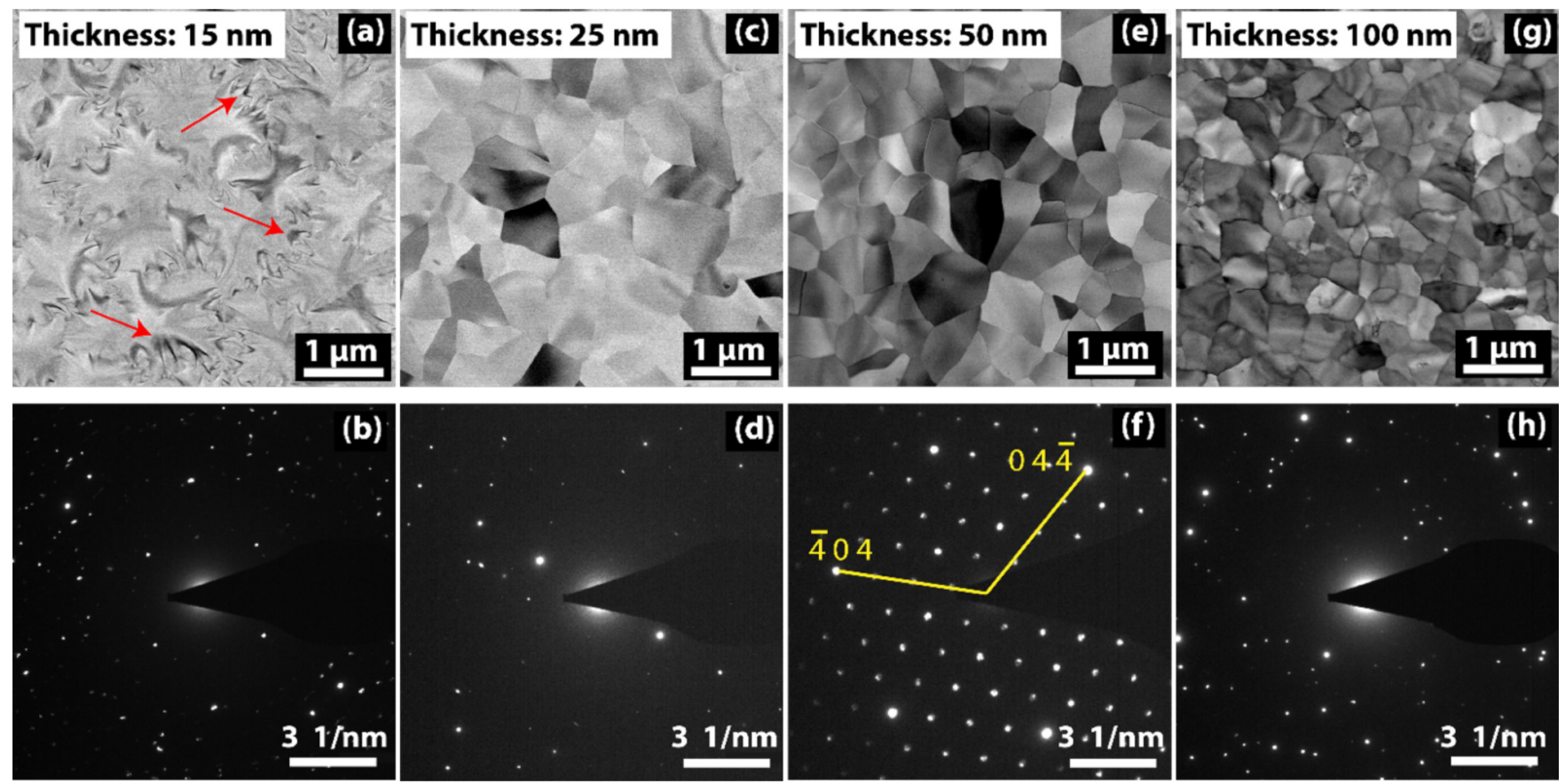

FIG. 4. STEM BF top view of (a) 15, (c) 25, (e) 50, and (g) 100-nm-thick films and their corresponding electron diffraction patterns in (b), (d), (f), and (h), respectively. 15-nm-thick films show a strained crystalline microstructure, while for thicker films, smaller crystallites are formed. Average crystallite sizes of 590, 340, and $260 \mathrm{~nm}$ are found for 25, 50, and 100-nm-thick films, respectively. The electron diffraction for (f) was performed in one single crystalline domain.

compared to the as-deposited and air-annealed films [Figs. 1(c) and 1(d)]. The link between defects and absorption centers has been observed previously [42,46-48]. All considered layers nonetheless show an absorptance below $4 \%$ in the visible range.

Focusing on the most relevant films and 400 to $1000 \mathrm{~nm}$ wavelength range, the 100-nm-thick air-annealed film presents an absorptance below $2 \%$ in spite of its sheet resistance below $25 \Omega /$ sq. The absorptance further decreases when reducing the film thickness, yet more strongly than expected from Beer-Lambert law especially in the infrared part of the spectra. This could be attributed to the reduced free-carrier density when reducing the thickness. For the 15 -nm-thick films, the absorptance is indistinguishable from that of the glass for wavelengths above $450 \mathrm{~nm}$ for all the annealing atmospheres. Still these films remain conductive, with the lowest sheet resistance $(\sim 500 \Omega /$ sq) being reached after $\mathrm{H}_{2}$ annealing ( $\mu$ of $50 \mathrm{~cm}^{2} \mathrm{~V}^{-1} \mathrm{~s}^{-1}$ ), making such layer of interest when high transparency is required.

\section{Polycrystalline films: Evolution of microstructure and electrical transport with film thickness}

Figure 4 shows top-view STEM bright-field (BF) micrographs of the polycrystalline air-annealed $\mathrm{In}_{2} \mathrm{O}_{3}: \mathrm{Zr}$ films for each film thickness. The 15-nm-thick films show a strained polycrystalline microstructure, as highlighted by the presence of bend contours [49], which gives rise to contrast in the images and makes a reliable grain size assessment more difficult. Increasing the thickness of the films up to 25 and $50 \mathrm{~nm}$ results in the formation of large crystalline grains with average sizes between 200 and $500 \mathrm{~nm}$. Grains are thus one order of magnitude larger along the specimen plane than the thickness of the films. Doubling the thickness up to $100 \mathrm{~nm}$ results in slightly smaller grain sizes. The SAED in Fig. 4(f) is for a single grain with an orientation [111], while the ones shown in Figs. 4(b), 4(d), and 4(h) include more than one crystalline domain (all the patterns were indexed by the $\mathrm{In}_{2} \mathrm{O}_{3}$ bixbyite atomic structure using the software JEMS).

It is proposed that the grain size after annealing is directly dependent on the density of crystalline seeds in the as-deposited state. Indeed, these low temperature annealing conditions trigger the growth of the existing crystalline domains but not the nucleation of new ones. Upon annealing, these nanocrystallites will grow until impingement, forming a closed packed arrangement of crystalline grains. Based on STEM micrographs and diffraction patterns of as-deposited films for all studied thicknesses, the increasing number of crystalline seeds with thickness is confirmed (data available in the Supplemental Material [34]). Thinner films therefore feature a lower number of seeds and hence larger grains after annealing. A similar crystallization mechanism was proposed for ALD-grown $\mathrm{In}_{2} \mathrm{O}_{3}: \mathrm{H}$ films [50].

Although a clear change in the optoelectronic properties is observed with decreasing thickness, all air-annealed films contain large crystalline grains. Also, the largest average grain sizes (for the 25-nm-thick film) do not directly correlate to the highest electron mobility measured for films $100 \mathrm{~nm}$ thick. This indicates that carrier transport is not limited by grain boundaries but by other defects, as it will be elaborated below.

To investigate the dominating scattering mechanisms for the air-annealed, polycrystalline films of each thickness, temperature-dependent Hall effect measurements were performed from -200 to $70{ }^{\circ} \mathrm{C}$. Scattering from grain 


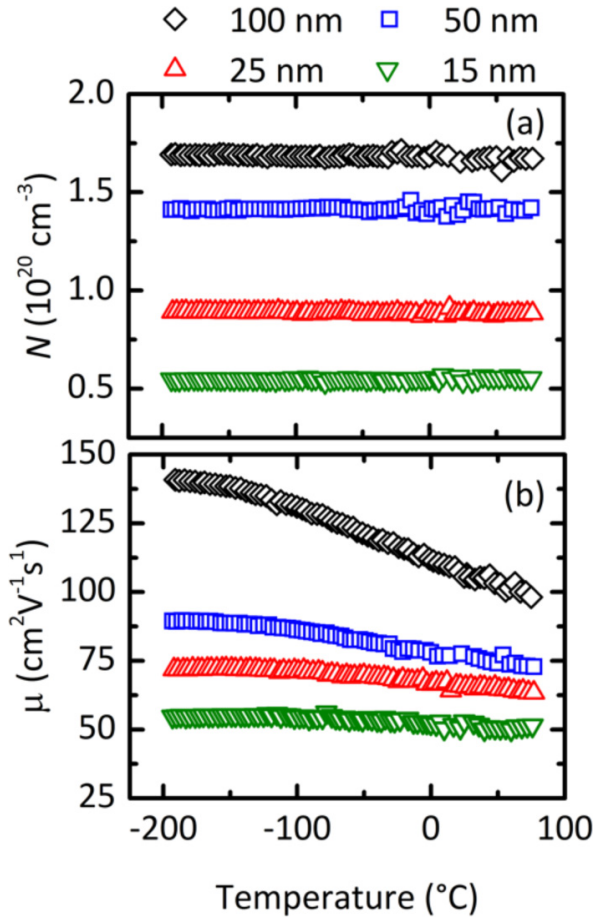

FIG. 5. Free-carrier density (a) and Hall mobility (b) as a function of temperature for air-annealed $\operatorname{In}_{2} \mathrm{O}_{3}: \mathrm{Zr}$ films with a thickness of $100,50,25$, or $15 \mathrm{~nm}$. While the free-carrier density does not change in this temperature range, the mobility of these different films changes with temperature. Thicker films exhibit a larger temperature dependent mobility, possibly due to a higher influence of optical phonon scattering compared to thinner films where ionized impurities dominate.

boundaries, optical phonons, and ionized impurities are the most common mechanisms limiting the transport of free electrons in degenerate TCOs. The first two mechanisms are temperature dependent, whereas ionized-impurity scattering is not. The contribution of each mechanism to the total mobility can be expressed by applying Matthiessen's rule:

$$
\frac{1}{\mu_{T}}=\frac{1}{\mu_{\mathrm{GB}}}+\frac{1}{\mu_{\mathrm{Ph}}}+\frac{1}{\mu_{\mathrm{ii}}},
$$

where $\mu_{T}$ is the total mobility, $\mu_{\mathrm{GB}}$ is the mobility limited by grain boundaries, $\mu_{\mathrm{Ph}}$ is the mobility limited by optical phonon scattering, and $\mu_{\mathrm{ii}}$ is the mobility limited by ionized impurities. The temperature dependence of the overall mobility can therefore shine light on the weight of each scattering mechanism. Scattering due to acoustic phonons and neutral impurities were not considered as they have been consistently demonstrated to have a negligible influence on carrier scattering for several doped $\operatorname{In}_{2} \mathrm{O}_{3}$ films [14].

Figure 5 shows the $N_{e}$ and $\mu$ for all air-annealed films with 100, 50, 25, and $15 \mathrm{~nm}$ thickness. As shown in Fig. 5, the $N_{e}$ of all films remains unchanged for the measured temperature range, which is expected for degenerately doped films. Regarding electron mobility, $\mu$ shows a transition from a temperature-independent behavior for the 15-nm-thick films, to a clear temperature dependence for 100 -nm-thick films, showing a decrease in $\mu$ with increasing temperature. This temperature dependency follows the power law $\mu \propto T^{-p}$,

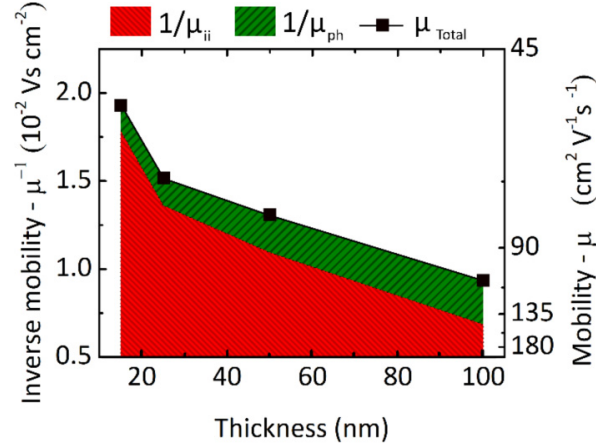

FIG. 6. Inverse mobility (left axis) as a function of thickness. The contribution from phonon scattering (green) and ionized impurities (red) was calculated by fitting Eq. (3). The right axis shows the Hall mobility (black squares) as a function of film thickness.

which describes electron-phonon interactions, i.e., optical phonon scattering $[13,14]$. For the slope between -130 and $70{ }^{\circ} \mathrm{C}$ the estimated factor $p$ for the 100 -nm-thick layer is $\sim 0.2$. This is lower than the $p \sim 2$ for purely electronphonon interactions in metals or degenerate semiconductors at temperatures below the Debye temperature $(700 \mathrm{~K}$ reported for $\operatorname{In}_{2} \mathrm{O}_{3}$ [14,51]). The lower slope therefore implies that, although dominating in 100-nm-thick films, phonon scattering is not the sole source of carrier scattering. Likely the second source is ionized impurities, whose influence become more relevant when reducing the film thickness, as described below. Note that for the range -200 to $-130{ }^{\circ} \mathrm{C}$ there seems to be a gradual change of slope towards a temperature-independent behavior, which may indicate a slight increased contribution from ionized impurities as well.

As mentioned above, scattering by grain boundaries is nondominating (or not present) in these films. This is evident by the temperature behavior of the mobility, which is opposite to what is expected when grain boundary scattering is dominating [ $\mu_{\mathrm{GB}} \propto \exp \left(E_{\mathrm{GB}} / k T\right)$, with $E_{\mathrm{GB}}$ the energy barrier to overcome the depleted region at the grain boundaries]. This follows similar behavior reported for other high $\mu$ In-based oxides [11,29,40,41].

To deconvolve the different contributions from phonon scattering $\left(\mu_{\mathrm{ph}},\right)$ and ionized impurity scattering $\left(\mu_{\mathrm{ii}}\right)$ to the total mobility [52,53], we rewrote the expression for Matthiessen's rule for each of the dominating mechanisms, becoming

$$
\frac{1}{\mu(T)}=\frac{1}{\mu_{0}}\left(\frac{T_{0}}{T}\right)^{2}+\frac{1}{\mu_{\mathrm{ii}}},
$$

where $\frac{1}{\mu_{0}}\left(\frac{T_{0}}{T}\right)^{2}$ is the mobility limited solely by phonon scattering (i.e., $p=2$ ). Using the data from Fig. 5 and Eq. (2), we obtained the contribution from each of the scattering sources, which is visualized in Fig. 6.

The latter shows that ionized impurity scattering dominates $\mu$ for the thinnest films, whereas ionized impurity and phonon scattering have a comparable contribution to scattering for the 100 -nm-thick films. The stronger influence of ionized impurities scattering for thinner films likely results from surface defects. 
Defects and a larger density of ionized impurities are expected at the surfaces of the $\mathrm{In}_{2} \mathrm{O}_{3}: \mathrm{Zr}$ films [54,55]. Regarding extrinsic impurities, bixbyite-type lattices show a high mobility of atomic oxygen [40] and a higher number of interstitial and substitutional sites for oxygen than other $n$-type structures [39]. The mobile $\mathrm{O}$ atoms lead to the passivation of $\mathrm{V}_{\mathrm{O}}{ }^{++}$and to the formation of other oxygen related impurities such as oxygen interstitial and substitutional oxygen $\left(\mathrm{O}_{\mathrm{i}}{ }^{-}\right.$and $\left.\mathrm{O}_{\mathrm{In}}{ }^{-}\right)$ [56] near the surface of the films. These defect species affect the overall electrical properties of thinner films (thickness $<100 \mathrm{~nm}$ ), since the passivation of $\mathrm{V}_{\mathrm{O}}^{++}$by the excess oxygen is reflected in a decrease of $N_{e}$ [Fig. 2(a)]. Conversely, the ionic nature of adsorbed $\mathrm{O}_{\mathrm{i}}^{-}$and $\mathrm{O}_{\mathrm{In}}{ }^{-}$further limits $\mu$ for thin films, as they might increase the rate of scattering events of the conduction electrons.

Following Look et al. [57], we applied a phenomenological model describing interface/surface scattering and the thickness dependence of mobility. The proposed model follows the relation

$$
\mu(d)=\frac{\mu(\infty)}{1+\frac{d^{*}}{d+\delta d}},
$$

where $\mu$ is the mobility of electrons in the bulk of the material (in the absence of surface defects), $d$ is the thickness of the films, $\delta d$ is the thickness of the depletion layer, $d^{*}$ is the thickness at which the $\mu$ is half of the bulk value $[\mu(\infty) / 2]$, i.e., it describes the quality of the interface or surface. By fitting the $\mu$ vs thickness data from Fig. 2(b) with Eq. (3), we found the best fit for $\delta d$ of $7.6 \mathrm{~nm}, \mu(\infty)$ of $126 \mathrm{~cm}^{2} \mathrm{~V}^{-1} \mathrm{~s}^{-1}$, and $d^{*}$ of $31 \mathrm{~nm}$ (fitting curve is shown in Fig. 6 of the Supplemental Material [34]). The $\delta d$ is an estimation of the thickness of a superficial low $\mu$ section of the film, which is affected by the aforementioned surface defects. A $\delta d$ of $7.6 \mathrm{~nm}$ represents half of the thinner $15 \mathrm{~nm}$ films and can therefore strongly influence the electron transport in these films, limiting its $\mu$ to $50 \mathrm{~cm}^{2} \mathrm{~V}^{-1} \mathrm{~s}^{-1}$ as seen in Fig. 5. The influence of $\delta d$ decreases in thicker films, since the high- $\mu$ region (bulk) becomes more important in the overall electron transport of the film. This results in the highest $\mu$ being reached here for the 100-nm-thick films when the limiting transport mechanism shifts from ionized impurities to optical phonon scattering.

\section{SUMMARY}

Sputtered $\mathrm{Zr}$-doped $\mathrm{In}_{2} \mathrm{O}_{3}$ films with a thickness varying from 100 to $15 \mathrm{~nm}$ and submitted to thermal treatments in various atmospheres were studied and a relation between microstructure, thickness, and optoelectronic properties is proposed. Annealing the films in air results in high-quality crystalline grains, with oxygen playing an important role for oxygen vacancies passivation and promoting crystallization. This results in 100-nm-thick films with a $\mu$ of $104 \mathrm{~cm}^{2} \mathrm{~V}^{-1} \mathrm{~s}^{-1}$ and a $N_{e}$ of $2.5 \times 10^{20} \mathrm{~cm}^{-3}$, leading to a sheet resistance of $25 \Omega$ /sq with exceptionally low absorptance in the nearUV-to-near-IR part of the spectrum. For films annealed in air, carrier transport is found to be limited by optical phonons and ionized impurity scattering. The latter becomes dominant for films with a thickness $<50 \mathrm{~nm}$ since these films are more sensitive to surface defects. Thermal treatments in reducing atmospheres are optimal to achieve high conductivity with thin films $(<50 \mathrm{~nm})$ as they maintain a high free carrier concentration. Conductivities as high as $1980 \mathrm{~S} \mathrm{~cm}^{-1}$ are achieved for 25-nm-thick films which have an optical absorptance close to the bare glass substrate. These highly conducting films with only few tens of nm could potentially trigger a new generation of transparent electrodes that reduce the usage of indium, present minimum absorption losses but are still produced with an industry-compatible technique.

\section{ACKNOWLEDGMENTS}

This work was funded by the Swiss National Science Foundation project DisCO (No CRSII2_154474). The authors want to thank Sylvain Dunand, Raphael Monnard, and Guillaume Charitat for the system support and Jérémie Werner for the fruitful discussion. In addition, the authors want to thank the personnel of EPFL CIME for their support and the access to electron microscopes.
[1] M. Morales-Masis, S. De Wolf, R. Woods-Robinson, J. W. Ager, and C. Ballif, Transparent electrodes for efficient optoelectronics, Adv. Electron. Mater. 3, 1600529 (2017).

[2] C. Battaglia, A. Cuevas, and S. De Wolf, High-efficiency crystalline silicon solar cells: Status and perspectives, Energy Environ. Sci. 9, 1552 (2016).

[3] S. Calnan and A. N. N. Tiwari, High mobility transparent conducting oxides for thin film solar cells, Thin Solid Films 518, 1839 (2010).

[4] D. S. Ginley and J. D. Perkins, Handbook of transparent conductors, in Handbook of Transparent Conductors, (Springer, Berlin, 2011), p. 1.

[5] K. Ellmer, Past achievements and future challenges in the development of optically transparent electrodes, Nat. Photon. 6, 808 (2012).

[6] A. Klein, Transparent conducting oxides: Electronic structureProperty relationship from photoelectron spectroscopy with in situ sample preparation, J. Am. Ceram. Soc. 96, 331 (2013).
[7] N. Yamada, I. Yasui, Y. Shigesato, H. Li, Y. Ujihira, and K. Nomura, Donor compensation and carrier-transport mechanisms in tin-doped $\mathrm{In}_{2} \mathrm{O}_{3}$ films studied by means of conversion electron ${ }^{119} \mathrm{Sn}$ Mössbauer spectroscopy and Hall effect measurements, Jpn. J. Appl. Phys. 39, 4158 (2000).

[8] T. Koida and M. Kondo, Improved near-infrared transparency in sputtered $\mathrm{In}_{2} \mathrm{O}_{3}$-based transparent conductive oxide thin films by Zr-doping, J. Appl. Phys. 101, 063705 (2007).

[9] T. Koida, M. Kondo, K. Tsutsumi, A. Sakaguchi, M. Suzuki, and $\mathrm{H}$. Fujiwara, Hydrogen-doped $\operatorname{In}_{2} \mathrm{O}_{3}$ transparent conducting oxide films prepared by solid-phase crystallization method, J. Appl. Phys. 107, 033514 (2010).

[10] H. Wardenga, M. Frischbier, M. Morales-Masis, and A. Klein, In situ Hall effect monitoring of vacuum annealing of $\operatorname{In}_{2} \mathrm{O}_{3}: \mathrm{H}$ thin films, Materials (Basel) 8, 561 (2015).

[11] G. C. E. Jost, A. N. Hamri, F. Köhler, and J. Hüpkes, Reliability aspects of hydrogen-doped indium oxide, Phys. Status Solidi 213, 1751 (2016). 
[12] M. Mizuno, T. Miyamoto, T. Ohnishi, and H. Hayashi, Effects of tin doping and oxygen vacancies on the electronic states of indium oxide, Jpn. J. Appl. Phys. 36, 3408 (1997).

[13] B. Macco, H. C. M. Knoops, and W. M. M. Kessels, Electron scattering and doping mechanisms in solid-phase-crystallized $\mathrm{In}_{2} \mathrm{O}_{3}: \mathrm{H}$ prepared by atomic layer deposition, ACS Appl. Mater. Interfaces 7, 16723 (2015).

[14] N. Preissler, O. Bierwagen, A. T. Ramu, and J. S. Speck, Electrical transport, electrothermal transport, and effective electron mass in single-crystalline $\mathrm{In}_{2} \mathrm{O}_{3}$ films, Phys. Rev. B 88, 085305 (2013).

[15] S. Limpijumnong, P. Reunchan, A. Janotti, and C. G. Van De Walle, Hydrogen doping in indium oxide: An ab initio study, Phys. Rev. B 80, 193202 (2009).

[16] M. Boccard, N. Rodkey, and Z. C. Holman, Properties of hydrogenated indium oxide prepared by reactive sputtering with hydrogen gas, in IEEE 43rd Photovoltaic Specialists Conference (PVSC) 2016 (IEEE, Piscataway, NJ, 2016), pp. 2868-2870.

[17] M. Boccard, N. Rodkey, and Z. C. Holman, High-mobility hydrogenated indium oxide without introducing water during sputtering, Energy Proc. 92, 297 (2016).

[18] C. Warmsingh, Y. Yoshida, D. W. Readey, C. W. Teplin, J. D. Perkins, P. A. Parilla, L. M. Gedvilas, B. M. Keyes, and D. S. Ginley, High-mobility transparent conducting Mo-doped $\operatorname{In}_{2} \mathrm{O}_{3}$ thin films by pulsed laser deposition, J. Appl. Phys. 95, 3831 (2004).

[19] T. Koida, Y. Ueno, and H. Shibata, $\mathrm{In}_{2} \mathrm{O}_{3}$-based transparent conducting oxide films with high electron mobility fabricated at low process temperatures, Phys. Status Solidi Appl. Mater. Sci. 215, 1700506 (2018).

[20] E. Kobayashi, Y. Watabe, and T. Yamamoto, High-mobility transparent conductive thin films of cerium-doped hydrogenated indium oxide, Appl. Phys. Express 8, 015505 (2015).

[21] P. F. Newhouse, C.-H. Park, D. A. Keszler, J. Tate, and P. S. Nyholm, High electron mobility W-doped $\operatorname{In}_{2} \mathrm{O}_{3}$ thin films by pulsed laser deposition, Appl. Phys. Lett. 87, 112108 (2005).

[22] Y. Meng, X.-L. Yang, H.-X. Chen, J. Shen, Y.-M. Jiang, Z.-J. Zhang, and Z.-Y. Hua, A new transparent conductive thin film $\mathrm{In}_{2} \mathrm{O}_{3}$ :Mo, Thin Solid Films 394, 218 (2001).

[23] H. Kim, J. S. Horwitz, G. P. Kushto, S. B. Qadri, Z. H. Kafafi, and D. B. Chrisey, Transparent conducting Zr-doped $\operatorname{In}_{2} \mathrm{O}_{3}$ thin films for organic light-emitting diodes, Appl. Phys. Lett. 78, 1050 (2001).

[24] T. Koida and M. Kondo, High-mobility transparent conductive Zr-doped $\mathrm{In}_{2} \mathrm{O}_{3}$, Appl. Phys. Lett. 89, 082104 (2006).

[25] T. Koida and M. Kondo, Comparative studies of transparent conductive Ti-, Zr-, and $\mathrm{Sn}$-doped $\mathrm{In}_{2} \mathrm{O}_{3}$ using a combinatorial approach, J. Appl. Phys. 101, 063713 (2007).

[26] Y. Kanai, Electrical properties of $\mathrm{In}_{2} \mathrm{O}_{3}$ single crystals doped with metallic donor impurity, Jpn. J. Appl. Phys. 23, 127 (1984).

[27] R. D. Shannon, Revised effective ionic radii and systematic studies of interatomic distances in halides and chalcogenides, Acta Crystallogr. Sect. A 32, 751 (1976).

[28] E. L. Runnerstrom, A. Bergerud, A. Agrawal, R. W. Johns, C. J. Dahlman, A. Singh, S. M. Selbach, and D. J. Milliron, Defect engineering in plasmonic metal oxide nanocrystals, Nano Lett. 16, 3390 (2016).

[29] E. Aydin, M. De Bastiani, X. Yang, M. Sajjad, F. Aljamaan, Y. Smirnov, M. N. Hedhili, W. Liu, T. G. Allen, L. Xu, E. Van Kerschaver, M. Morales-Masis, U. Schwingenschlögl, and S.
De Wolf, Zr-doped indium oxide (IZRO) transparent electrodes for perovskite-based tandem solar cells, Adv. Funct. Mater. 29, 1901741 (2019).

[30] M. Morales-Masis, E. Rucavado, R. Monnard, L. Barraud, J. Holovský, M. Despeisse, M. Boccard, and C. Ballif, Highly conductive and broadband transparent $\mathrm{Zr}$-doped $\mathrm{In}_{2} \mathrm{O}_{3}$ as front electrode for solar cells, IEEE J. Photovoltaics 8, 1202 (2018).

[31] P. Schlossmacher, D. O. Klenov, B. Freitag, and H. S. von Harrach, Enhanced detection sensitivity with a new windowless XEDS system for AEM based on silicon drift detector technology, Micros. Today 18, 14 (2010).

[32] M. Nastasi, J. Mayer, and Y. Wang, Ion Beam Analysis: Fundamentals and Applications (CRC Press Taylor \& Francis Group, Boca Raton, FL, 2014).

[33] P. Stadelmann, EMA-a software package for electron diffraction analysis and HREM image simulation in materials science, Ultramicroscopy 21, 131 (1987).

[34] See Supplemental Material at http://link.aps.org/supplemental/ 10.1103/PhysRevMaterials.3.084608 for details RBS, EDX and STEM data as well as fitting procedures.

[35] R. M. Pasquarelli, M. F. A. M. Van Hest, P. A. Parilla, J. D. Perkins, R. O'Hayre, and D. S. Ginley, Processing-phase diagrams: A new tool for solution-deposited thin-film development applied to the $\mathrm{In}_{5} \mathrm{O}(\mathrm{OPri})_{13}-\mathrm{In}_{2} \mathrm{O}_{3}$ system, J. Mater. Chem. C 2, 2360 (2014).

[36] F. O. Adurodija, L. Semple, and R. Brüning, Crystallization process and electro-optical properties of $\mathrm{In}_{2} \mathrm{O}_{3}$ and ITO thin films, J. Mater. Sci. 41, 7096 (2006).

[37] J. E. Medvedeva, D. B. Buchholz, and R. P. H. Chang, Recent advances in understanding the structure and properties of amorphous oxide semiconductors, Adv. Electron. Mater. 3, 1700082 (2017).

[38] D. B. Buchholz, Q. Ma, D. Alducin, A. Ponce, M. J.-Yacaman, R. Khanal, J. E. Medvedeva, and R. P. H. Chang, The structure and properties of amorphous indium oxide, Chem. Mater. 26, 5401 (2014).

[39] S. P. Harvey, T. O. Mason, Y. Gassenbauer, R. Schafranek, and A. Klein, Surface versus bulk electronic/defect structures of transparent conducting oxides: I. Indium oxide and ITO, J. Phys. D. Appl. Phys. 39, 3959 (2006).

[40] P. Ágoston and K. Albe, Ab initio modeling of diffusion in indium oxide, Phys. Rev. B 81, 195205, (2010).

[41] E. Rucavado, Q. Jeangros, D. F. Urban, J. Holovský, Z. Remes, M. Duchamp, F. Landucci, R. E Dunin-Borkowski, W. Körner, C. Elsässer, A. Hessler-Wyser, M. Morales-Masis, and C. Ballif, Enhancing the optoelectronic properties of amorphous zinc tin oxide by subgap defect passivation: A theoretical and experimental demonstration, Phys. Rev. B 95, 245204 (2017).

[42] T. Kamiya, K. Nomura, and H. Hosono, Origins of high mobility and low operation voltage of amorphous oxide TFTs: Electronic structure, electron transport, defects and doping, J. Disp. Technol. 5, 273 (2009).

[43] P. D. C. King and T. D. Veal, Conductivity in transparent oxide semiconductors, J. Phys. Condens. Matter 23, 334214 (2011).

[44] T. Bielz, H. Lorenz, W. Jochum, R. Kaindl, F. Klauser, B. Klötzer, and S. Penner, Hydrogen on $\operatorname{In}_{2} \mathrm{O}_{3}$ : Reducibility, bonding, defect formation, and reactivity, J. Phys. Chem. C 114, 9022 (2010).

[45] C. G. Van de Walle, Hydrogen as a Cause of Doping in Zinc Oxide, Phys. Rev. Lett. 85, 1012 (2000). 
[46] M. Himmerlich, C. Y. Wang, V. Cimalla, O. Ambacher, and S. Krischok, Surface properties of stoichiometric and defect-rich indium oxide films grown by MOCVD, J. Appl. Phys. 111, 093704 (2012).

[47] W. Körner, D. F. Urban, and C. Elsässer, Origin of subgap states in amorphous In-Ga-Zn-O, J. Appl. Phys. 114, 163704 (2013).

[48] M. Morales-Masis, S. Martin De Nicolas, J. Holovsky, S. De Wolf, and C. Ballif, Low-temperature high-mobility amorphous IZO for silicon heterojunction solar cells, IEEE J. Photovoltaics 5, 1340 (2015).

[49] D. B. Williams and C. B. Carter, Transmission Electron Microscopy, A Text Book for Materials Science (Plenum, New York, 1996).

[50] B. Macco, M. A. Verheijen, L. E. Black, B. Barcones, J. Melskens, and W. M. M. Kessels, On the solid phase crystallization of $\mathrm{In}_{2} \mathrm{O}_{3}: \mathrm{H}$ transparent conductive oxide films prepared by atomic layer deposition, J. Appl. Phys. 120, 085314 (2016).

[51] A. K. Das, P. Misra, R. S. Ajimsha, A. Bose, S. C. Joshi, D. M. Phase, and L. M. Kukreja, Studies on temperature dependent semiconductor to metal transitions in $\mathrm{ZnO}$ thin films sparsely doped with Al, J. Appl. Phys. 112, 103706 (2012).

[52] J. S. Dugdale, The Electrical Properties of Metals and Alloys (E. Arnold London, London, 1977).

[53] D. H. Zhang and H. L. Ma, Scattering mechanisms of charge carriers in transparent conducting oxide films, Appl. Phys. A Mater. Sci. Process. 62, 487, 1996.

[54] S. M. Sze, Physics of Semiconductor Devices, 2nd ed. (John Wiley \& Sons, New York, 1981).

[55] K. T. Butler, J. Buckeridge, C. Richard, A. Catlow, and A. Walsh, Crystal electron binding energy and surface work function control of tin dioxide, Phys. Rev. B 89, 115320 (2014).

[56] P. Ágoston, P. Erhart, A. Klein, and K. Albe, Geometry, electronic structure and thermodynamic stability of intrinsic point defects in indium oxide, J. Phys. Condens. Matter 21, 455801 (2009).

[57] D. C. Look, K. D. Leedy, A. Kiefer, B. Claflin, N. Itagaki, K. Matsushima, and I. Surhariadi, Model for thickness dependence of mobility and concentration in highly conductive zinc oxide, Opt. Eng. 52, 033801 (2013). 